\title{
Improving Maternal Role on Toddler Oral Hygiene in Integrated Service Center (Posyandu) Beber, Cirebon, Indonesia through Participatory Approach Assistance
}

\author{
Yenny Lisbeth Siahaan ${ }^{1 *}$, Sekar Restuning ${ }^{2}$, Ni Made Yuliana ${ }^{3}$, Jendri Mamangkey ${ }^{4}$ \\ ${ }^{1}$ Health Polytechnic, Ministry of Health Medan of Department of Dental Health, Indonesia \\ ${ }^{2}$ Dental Care Major, Health Polytechnic, Ministry of Health, Bandung, Indonesia \\ ${ }^{3}$ Dental Care Major, Health Polytechnic, Ministry of Health, Manado, Indonesia \\ ${ }^{4}$ Departement of Biology Education, Faculty of Education and Teacher Training, Universitas \\ Kristen Indonesia. J1. Mayjen Sutoyo No.3, Cawang, Jakarta 13510, Indonesia \\ ${ }^{*}$ Corresponding author: \\ Email: yennilisbeth@gmail.com
}

\begin{abstract}
.
Poor dental health on children including caries causes pain and difficulty in chewing. This study aimed to analyze the effect of assistance model on mothers to impove toddler oral health aged 2-5 years old. This research employed quasiexperiment through pretest and posttest approach intervention. The samples were mothers having 2-5 years old toddlers who met inclusion criteria including having PHP-M teeth index score of 40, willing to be involved, the mothers have at least junior high school education level and living in the Posyandu are. Meanwhile, the exclusion criteria was mothers who rarely visited Posyandu. Furthermore, data were analyzed using univariate and bivariate. If the data were not normally distributed, then Wilcoxon test would be done. Difference obtained between before and after the assistance model was provided to the mothers with significance value of $p=0.001 \quad(p<0.05)$. This indicates that assistance model caused changes on mothers' knowledge at Posyandu. Same results were obtained from attitude, skills and PHP-M index score before and after the intervention with significance value of $P=0.001$ ( $p<0.05)$. This shows that assistance model caused changes on attitude, skills and decrease of toddlers' PHP-M index score at Posyandu Beber. The outcome of the current research obtained that assistance model is proven to be more effective in improving toddler oral hygiene than extension that was carried out at Posyandu.

Keywords: Assistance, dental and oral health, Posyandu
\end{abstract}

\section{INTRODUCTION}

Serious concern needs to be provided on Indonesian oral hygiene from health observer, both dentist and dental nurse. Data issued by World Health Organization (WHO) through the World Oral Health Report showed that 90\% of Indonesian people still suffered from dental and oral disease. Furthermore, based on the Basic Health Research 2013, caries prevalence through Decayed Missing Filled Teeth examination method showed that $25.9 \%$ Indonesian people had oral health problems.

This is supported by another previous research performed by Zaura Rini in Jakarta mentioning that $80 \%$ Indonesian people suffered from cavities disease [1]. Dental cavities was also found in Public Health Center of Beber in 2012, in which 78\% 
toddlers suffered from cavities. Cavities caused by plaque is frequently found on children under five years old (toddlers), with the highest distribution on three years old toddlers [2].

Mothers with low knowledge on toddler oral hygiene will affect the oral health and a behavioral predisposing factor which do not support the child's oral health [3]. Mother is the first and main environment where children interact as the foremost educational institution, meaning that this is where an educational process begins. So that the mother acts as an educator for her children.

Dental and oral health services are health services performed by the medical or health services executors authorized in the field of dental and oral health. The dental and oral health service program consists of in-building health services, which are dental polyclinic in the form of dental and oral health checks, promotive, preventive, and curative efforts. Unfortunately, the Posyandu implemented by the community has not been optimal. One of the activities that have not been carried out at Posyandu is the implementation of public dental health efforts.

Public Dental Health Efforts (UKGM) carried out in Posyandu are the same as activities conducted in the other Posyandu (such as activities concerning nutrition). Various efforts to improve nutrition have only been able to improve the nutritional status of children when the program is implemented, so that the malnutrition problem will remain. The same goes for the dental health status of toddlers. Based on the observations conducted by researchers in Posyandu Beber activities, all toddlers who had dental health problems and visited the Posyandu were only provided with counseling without any assistance from the officers to their homes.

Assistance by health workers which is implemented to home visits is an effort to equalize the mothers of toddlers in developing their various potentials in order to achieve a better health quality for toddlers, especially children's dental health towards a better direction. The assistance is aimed at helping mothers with toddlers in improving Posyandu activities as an effort to provide dental health for toddlers [5]. The assistance model provided in promotive health services is an activity and/or a series of health service activities that prioritize health education (counseling) activities.

Based on the results of the initial survey on the oral hygiene with a PHP-M score of 40 with poor criteria experienced by toddlers at Posyandu of Public Health Center Beber. So that researchers were interested in conducting research that aimed to improve the role of mothers in the oral hygiene of toddlers under five years old at Posyandu Beber, Cirebon, Indonesia with the participatory approach assistance.

\section{METHODS}

\section{Research Type and Design}

The research design used was a quasi-experiment with pre-test and post-test intervention approaches. This study was done to know the effects of the assistance models carried out on mothers of toddlers at Posyandu Beber in improving the dental hygiene status of toddlers. This study provided an intervention of assistance model treatment concerning the dental hygiene status of toddlers, in which the effect of the treatment was seen in differences in dental hygiene of toddlers under five years old (primary teeth) using the PHP-M index before and after treatment.

Treatment Group 


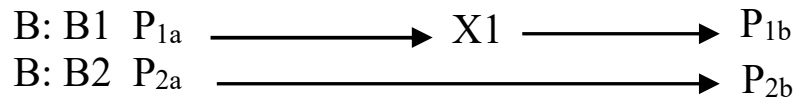

Explanation:

$\mathrm{B}=$ Toddlers in Posyandu

$\mathrm{B} 1=$ Toddlers in Posyandu from assistance model intervention group

B2 = Toddlers in Posyandu from counseling control group

$\mathrm{P}_{1 \mathrm{a}}=$ Observation on assistance model intervention group (pretest) included variables of knowledge, mothers' behavior, and children's dental hygiene level (index $=P H P$ $M)$

$\mathrm{P}_{1 \mathrm{~b}}=$ Observation on assistance model intervention group (posttest) included variables of knowledge, mothers' behavior, and children's dental hygiene level (index = PHP-M)

$\mathrm{X} 1=$ Assistance model intervention

$\mathrm{P}_{2 \mathrm{a}}=$ Observation on control group (pretest) included variables of knowledge, mothers' behavior, and children's dental hygiene level (index $=P H P-M)$

$\mathrm{P}_{2 \mathrm{~b}}=$ Observation on assistance model intervention group (pretest) included variables of knowledge, mothers' behavior, and children's dental hygiene level (index $=P H P$ M)

\section{Research Population and Sample}

The research population was all mothers who have toddlers at the age of 2-5 years old with a minimum education level of junior high school. There were 2 Posyandu (Posyandu RW IV and Posyandu RW V) in the working area of the Puskesmas with the number of mothers and toddlers under five years old at each Posyandu was 25 mothers and 25 toddlers, so the total was 50 mothers and 50 toddlers under five years old.

The research samples were chosen based on the mothers who had toddlers aged 2-5 years old and met the inclusion criteria, including toddlers who had PHP-M index teeth with a score of 40, were willing to be the research sample, and mothers with a minimum education level of junior high school in the Posyandu working area. Meanwhile, for the exclusion criteria was mothers who passively bring their toddlers to Posyandu. The sampling technique was carried out using purposive sampling, while the sample size in simple experimental research using control and treatment groups was 10-20 for each group and in this study, the number of samples used was 15 for each group $[6,7]$.

\section{Data Analysis}

This study employed parametric test due to the numerical data scale. The purpose of the analysis was to analyze the differences. Prior to conduct the analysis, normality test was performed by using Shapiro-Wilk since the sample was less than 50 samples. The bivariate analysis used was the paired $\mathrm{T}$ sample of dependent $\mathrm{t}$-test $\mathrm{t}$ to analyze the differences in the initial and final scores of the level of knowledge, attitudes, maternal skills, and toddler PHP-M. If the data is not normally distributed, then Wilcoxon test is selected. The significance level used was $\alpha=0.05$ and $95 \%$ confidence interval. 


\section{RESULT AND DISCUSSION}

\section{Measurement of Knowledge, Behavior, Skills and PHP-M of Toddlers}

Mother's knowledge from both groups before the assistance was categorized as poor by 8 people $(53.3 \%)$ in the intervention group and 10 people $(66.7 \%)$ in the control group. The attitudes of mothers in both intervention and control group were mostly in moderate category with 8 people (53.3\%) from intervention group and 14 people $(93.3 \%)$ from control group. Mother's skills in both intervention and control group were mostly in poor category, with 11 people $(73.3 \%)$ from intervention group and 15 people (100\%) from the control group. PHP-M index of toddlers in both intervention and control group were mostly at poor category with 9 people $(60.0 \%)$ from intervention group and 10 people (66.7\%) from control group. After the assistance was performed, maternal knowledge on the intervention group changed into good category by 15 people (100\%), while in the control group the poor category was 8 people (53.3\%). The attitudes of mothers in the intervention group were also in good category by 15 people $(100 \%)$, while mostly at the control group were in moderate group by 11 people $(73.3 \%)$. Skills in the intervention group were mostly in good category by 14 people (93.3\%), while in control group were all in poor category by 15 people $(100 \%)$. PHP-M of toddlers in the intervention group were mostly in the very good category by 8 people $(53.3 \%)$, while in the control group were mostly at poor category by 11 people (73.3).

Table 1. Changes of knowledge on mothers who received assistance and did not receive assistance on both intervention and control group

\begin{tabular}{ccccc}
\hline Group & \multicolumn{2}{c}{ Changes on Mother's Knowledge Score } & P value \\
& Mean \pm SD & Min & Max & \\
\cline { 1 - 4 } $\begin{array}{c}\text { Intervention } \\
(\mathrm{n}=15)\end{array}$ & $52.93 \pm 8.78$ & 34 & 67 & \multirow{2}{*}{0.001} \\
\cline { 1 - 4 } Control $(\mathrm{n}=15)$ & $34.73 \pm 12.40$ & 20 & 54 &
\end{tabular}

*independent t-test $\mathrm{p}<0,001$

Table 1 shows mean score of mothers who receive assistance model was Mean \pm SD $52.93 \pm 8.78$ while mothers who did not receive assistance obtained knowledge mean score of 34.73 (SD 12.40). Analysis result obtained p-value of 0.001 $(\mathrm{p}<0.05)$, so it can be summed up that there was differences on knowledge between mothers who received assistance and mothers who did not receive assistance.

\section{Changes on Mother's Attitude}

Table 2 shows that the mean score of the attitude of mothers who received assistance model was Mean \pm SD $43.53 \pm 12.33$ while mothers who did not receive assistance model was 3.53(SD 8.35). Analysis result obtained p-value of 0.001 $(\mathrm{p}<0.05)$. Therefore it can be summed up that there was difference on the attitude of mothers who received assistance and mothers who did not receive assistance.

Table 2: Changes on the Attitude of Mothers who received assistance and did not receive assistance on both intervention and control groups

\begin{tabular}{cccc} 
Groups & \multicolumn{2}{c}{ Changes on Mothers' Attitude Score } & $P$ value \\
\cline { 2 - 3 } & Mean \pm SD & Min Max
\end{tabular}




\begin{tabular}{lcccc}
\hline $\begin{array}{l}\text { Intervention } \\
(\mathrm{n}=15)\end{array}$ & $43.53 \pm 12.33$ & 20 & 67 & 0.001 \\
\cline { 1 - 3 } Control $(\mathrm{n}=15)$ & $3.53 \pm 8.35$ & 0 & 27 & \\
\hline
\end{tabular}

${ }^{*}$ Mann-whitney; $\mathrm{p}<0.001$

\section{Changes on Mothers' Skill}

Table 3 presents the analysis result of mothers' skill on the group who received assistance model obtaining mean score of 53.27 (SD 8.37), while the group who did not receive assistance model obtained mean score of 0.47 (SD 5.74). Based on the analysis result, the $\mathrm{p}$-value obtained was $\mathrm{p}=0.001(\mathrm{p}<0.05)$. Thus it can be summed up that no skills difference obtained between mothers who received assistance model and mothers who did not receive assistance model.

Table 3. Changes on Skills of mothers who received assistance model and mothers who did not receive assistance model on both intervention and control group

\begin{tabular}{lcccc}
\hline \multirow{2}{*}{ Groups } & \multicolumn{2}{c}{ Changes on Mothers' skill score } & P value \\
\cline { 2 - 4 } & Mean \pm SD & Min & Max & \\
Intervention $(\mathrm{n}=15)$ & $53.27 \pm 8.37$ & 41 & 67 & \\
\cline { 2 - 4 } control $(\mathrm{n}=15)$ & $0.47 \pm 5.74$ & 9 & 16 & \\
\hline & \multicolumn{4}{c}{ "Mann-whitney; $<<0.001$}
\end{tabular}

\section{Measurement of Toddler PHP-M}

Table 4 shows the analysis results on PHP-M of toddlers who received assistance model and toddlers who did not receive assistance model obtained p-value of 0.001 ( $p<0.05$ ), thus it can be summed up that there was no difference between toddlers who received and did not receive the assistance model.

Table 4. Changes on PHP-M of toddlers who received assistance model and did not receive assistance model on both intervention and control groups

\begin{tabular}{llccc}
\hline Groups & \multicolumn{2}{l}{ Changes of Toddler PHP-M Score } & P value \\
\cline { 2 - 4 } & Mean \pm SD & Min & Max & \\
Intervention $(\mathrm{n}=15)$ & $32.53 \pm 6.82$ & 20 & 45 & 0.001 \\
Control $(\mathrm{n}=15)$ & $-1.53 \pm 6.24$ & 12 & 8 & \\
\hline & & \multicolumn{4}{c}{ Independent Samples Test }
\end{tabular}

\section{Discussion}

The objective of this research was to analyze the effect of assistance through a participatory approach in improving the role of mothers about their toddler dental and oral hygiene at Posyandu Beber, Cirebon, Indonesia. Statistical analysis shows that there was a significant difference in the knowledge of mothers who received assistance and mothers who did not receive assistance in improving the dental and 
oral hygiene status of their toddlers. The results of the research were supported by previous research conducted in Sulawesi concerning the application of assistance models to improve the nutritional status of toddlers, in which the application of assistance brought changes on mother's knowledge score, TKE, and toddler nutritional status [5]. Knowledge change is basically and theoretically a learning process (Stimulus Organism Response/SOR). If the information is not provided intensively, periodically and continuously, it is possible that the respondent will return to its initial state [4].

In this research, assistance was provided for 3 weeks through three processes of home visits, which is the first process in which intensive empowerment was performed every day through discussions on things that were not understood yet. The learning focus was aimed at maintaining toddler oral hygiene (good and correct toothbrush technique, correct selection of toothbrushes for toddlers, correct toothbrush timing and frequency), a good diet for dental health, regular dental examinations to the nearest dental health service or Puskesmas. Second is reinforcement which aimed to provide reinforcement of the mothers' skills for what had been recommended by the assistant dental nurses or cadres, among others; Toothbrush techniques, toothbrush/toothpaste selection, as well as frequency and timing of toothbrushes on toddlers. The third is independent practice, which was carried out aiming to let the mothers to perform it independently without practical assistance regarding the instructions recommended by cadres, in terms of maintaining dental and oral hygiene in toddlers.

The research statistical data shows that there was a very significant difference in the attitudes of mothers who received assistance and who did not receive assistance in improving the dental and oral hygiene status of their toddlers. The Mann-Whitney test analysis results of the mothers' attitudes between the groups that received assistance and those who did not receive assistance obtained mean score of $p=0.001(p<0.05)$. Therefore, it can be concluded that there were differences in the attitudes of mothers who received assistance and those who did not receive assistance. Attitude is an accumulation of self-experience values or others' experience who are closest or important person.

Sustainable changes in attitude can change a mother's behavior where good behavior can improve the dental and oral hygiene status of their toddlers. Based on this result, it is clear that in the intervention area (assistance) there was a change in attitude in becoming better. This happened because the assistance process carried out by cadres was intensively provided so that it was easier for mothers to understand. The results of this study are in line with the research conducted by Sofiyana et al [8], which showed that there were differences in mother's attitudes before and after nutritional counseling conducted for 1 month with the assistance model where there was an increase in mother's knowledge with $\mathrm{p}$ value $=0.001$. Nutrition knowledge for mothers provided in the form of counseling with an assistance model can change the mother's attitude, which in turn can change the mother's behavior for the better and can improve the nutritional status of her child.

Statistical analysis result indicates that there was a very significant difference in the skills of mothers who received assistance and who did not receive assistance in improving the dental and oral hygiene status of toddlers. The Mann-Whitney test analysis results of the mother's skills between groups who received assistance and those who did not receive assistance obtained mean score of $p$ value $=0.020(p<0.05)$. 
Thus, it can be concluded that there were differences in the skills of mothers who received assistance and those who did not receive assistance. The results of this study are in line with research conducted at NTT Hospital (2001) stating that there was an effect of changes in skills carried out by the family assistance model in preventing infection of abdominal surgery wounds [9].

The current research was not only about knowledge and attitudes, but also the skills of mothers in carrying out dental and oral hygiene for the toddlers in the assistance process where mothers in the intensive phase were taught how to brush teeth, brushing techniques, time to brush teeth, and frequency of brushing teeth, until the last stage in which mothers were expected to be able to practice independently in maintaining oral hygiene of toddlers. This study has proven that mothers who have good knowledge also has a good attitude so that motivate them to take actions or skills according to the knowledge gained.

Based on the current research results, the maternal assistance model showed that the initial PHP-M of the toddlers before the assistance in both intervention and control groups were less sufficient and bad. This means that the knowledge, attitudes and skills of the mother have not been seen at the beginning of the examination of the oral hygiene of the toddlers. After the assistance was performed, it was seen that the decrease of toddler PHP-M was very good. Likewise, the results of statistical analysis showed that there was a very significant difference in toddler PHP-M who received assistance and those who did not receive assistance in improving the dental and oral hygiene status of the toddlers. The decrease in the toddler PHP-M score was caused by the increase in knowledge, attitudes and skills of the mother, which was better in the intervention group than in the control group, such as the knowledge of mothers on the appropriate way and time to brush their toddler teeth, healthy diet for their toddler teeth, visiting or bringing children to control dental health to the nearest health service (Puskesmas).

Assistance is a form of effort to include mothers of toddlers in developing their various potentials so as to achieve a better quality of dental and oral health for their toddlers. Assistance means help from outside parties, both individuals and groups to increase awareness in order to fulfill needs and solve problems, for example regarding the toddler oral health $[10,11]$. This implies that the role of the assistant is limited in providing alternatives, advice, and consulting assistance and not in making decisions.

Researchers considered that the assistance provided was very good for mothers who have toddlers. The impact that was felt is the mother's motivation and curiosity about the information that has been conveyed. Unconsciously, this fosters the willingness of the mother to increase knowledge, especially regarding the hygiene of the toddler dental and oral hygiene until the toddlers change their temporary teeth to permanent teeth. In the framework of this assistance, the relationship built by the companion is a consultative and participatory relationship. With this relationship, the role that the companion can play in carrying out the assistance function is the role of the motivator, facilitator and catalyst [12].

As the assistants in implementing Posyandu program, cadres are very much needed in achieving toddler dental health. Their main role as a facilitator is to help revive and develop a productive group of toddler mothers at Posyandu as a forum for improving the toddler dental health. The empowerment process that can be done are including social approach efforts that lead to social change by trying to create present 
and better future conditions. There are three main roles of cadres as assistants in the formation and development of Posyandu program, namely as transmitters, motivators, and liaisons. Assistance can be carried out with home visits through Posyandu program which reflects itself as an agent of reform. It is clear that the role and credibility of intervention assistance is needed in a Posyandu program $[13,14]$.

\section{CONCLUSION}

Based on the result of this study, it can be concluded that there is a difference in the knowledge value before and after the assistance model with a significant value of $p$ $=0.001(\mathrm{p}<0.05)$. This means that there is an effect of the assistance model on the knowledge changes of mothers visiting Posyandu Beber. The assistance carried out by cadres is basically an effort to motivate mothers of toddlers and involve them in developing various potential abilities of mothers possessed. Improved knowledge of dental and oral hygiene in toddlers will reflect good attitudes and actions towards toddler dental and oral hygiene. Furthermore, there was also a difference in the attitude value before and after the mother received assistance model with a significant $\mathrm{p}$ value $=0.001(\mathrm{p}<0.05)$, which means that there was an effect of the assistance model on the attitude changes of mothers who visited the Posyandu Beber. This research proved that respondents who have good knowledge will have a good attitude towards improving the toddler dental and oral hygiene status. A change in a better attitude occurs because the assistance process carried out by the cadres is intensively provided so that it is easier to understand by the toddler mothers and reflects good attitudes and actions towards toddler dental and oral hygiene.

The next conclusion is that there is a difference in the value of skills before and after the mother receiving assistance model with a significant value of $p=0.001$ ( $p$ $<0.05$ ), which means that there is an effect of the assistance model on changes in the skills of mothers visiting Posyandu Beber. Mother's skills reflect knowledge and attitudes in performing dental and oral hygiene for their toddlers. The assistance model carried outperformed by the cadres to mothers is intensive including how to brush teeth, brushing techniques, time to brush teeth, and the frequency of brushing teeth properly and correctly, so that mothers of the toddlers are able to practice independently in maintaining dental and oral hygiene for their toddlers. This positively affect on improving the oral hygiene status of the toddlers. Furthermore, the final conclusion is that there is a difference in the PHP-M value for toddlers before and after the assistance model was carried out for the toddlers. The assistance model has succeeded in providing motivation and ability for mothers to maintain toddler dental hygiene. It can be seen from the results obtained that the PHP-M value of toddlers has decreased in order to achieve the expected dental and oral hygiene status.

\section{ACKNOWLEDGMENTS}

The authors would like to thank Dental Health Major of Health Polytechnic Medan and Postgraduate Program of Applied Health Science Concentration, Universitas Diponegoro for supporting this research. This research was funded by DIPA of Health Polytechnic of Ministry of Health of the Republic of Indonesia Number: HK.03.05/I/V.3/09440/2012. 


\section{REFERENCES}

[1] Ghofar A, Firmansyah, Relationship between Dental Caries and Nutritional Status of Children of Kindergarten Muslimat 7 Petrongan Jombang, Journal Eduhealth. 2012; 2(2).

[2] Dye BA, Thornton-Evans-G. Trends in oral health by poverty status as measured by Healthy People. Public Health Rep. 2010; 125: 817-30.

[3] Maulani C and Enterprise J. Tips of Taking Care Children's Dental Health, Guidelines for Parents in Taking Care and Maintaining Children's Dental Health. EGC. 2005; 35-37

[4] Budiharto, Introduction to Healthy Behavioral Science and Dental Health Education Jakarta EGC. 2010; page 11-17.

[5] Amir, A. The Influence of Outreach Mode Counseling Toward Nutritional Status Change on 6- 24 Months Old Children. M Med Indones. 2008; 43(3): 148-55.

[6] Sugiono. Educational Research Method (Quantitative, Qualitative and Research \& Development Method). Alfabate. Bandung 2008. pp 130-132.

[7] Heri D.J. Maulana. Health Promotion. Jakarta. EGC. 2009. pp 148-150

[8] Sofiyana, D., Noer, E.R., Differences in knowledge, attitudes and behavior of mothers before and after nutritional counseling for malnourished infants, Journal of Nutrition College, 2(1), pp. 134-144

[9] Mau A., The Effect of Patient Family Empowerment through Education on Changes in the Ability of Family Members in Preventing Abdominal Surgery Wound Infection at Home. Master Thesis Universitas Airlangga. Surabaya, 2011. pp 85-86

[10] Dewi, Dian K. Proses Assistance in Community Empowerment Programs. Undergraduate Thesis. Department of Social Welfare Science. Faculty of Social Science and Political Science. Universitas Indonesia. Depok. 2008

[11] Anggraeni S. The Effect of Nutrition Assistance on Food Shopping on Changes in Nutritional Status for Babies aged 6-12 Months in Stimulant Fund Households. PostGraduate Program of Universitas Diponegoro Semarang 2011

[12] Subagyo H. The Influence of Village Midwife Assistance Role on the Development of Alert Village in Blitar District [M.Si. Thesis]. Universitas Sebelas Maret Surakarta. 2008

[13] Yusri, Ahmad. Factors Affecting Farmers' Perceptions of Agricultural Extension Credibility. Master Thesis. Postgraduate Program of Bogor Agricultural Institute. 1999.

[14] Suranto, Anto. IDT Community Group Members Attitude (POKMAS) Towards the Roles and Characteristics of Facilitators (Case Study in the Governor Assistant Region of Central Java, Surakarta Region). Master Thesis. Postgraduate Program. Bogor Agricultural Institute. 1997. 